Brazilian Journal

of Chemical

\title{
EVALUATION OF CYCLONE GEOMETRY AND ITS INFLUENCE ON PERFORMANCE PARAMETERS BY COMPUTATIONAL FLUID DYNAMICS (CFD)
}

\author{
W. P. Martignoni ${ }^{1}$, S. Bernardo ${ }^{2}$ and C. L.Quintani ${ }^{3}$ \\ ${ }^{1}$ Petróleo Brasileiro S.A., PETROBRAS, AB-RE/TR/OT, Phone: +(55) (21) 3224-4255, Fax: +(55) (21) 3224-1767, \\ Av. República do Chile 65, Sala 2102, Centro, CEP: 20031-912, Rio de Janeiro - RJ, Brazil. \\ E-mail: martignoni@petrobras.com.br, \\ ${ }^{2}$ Instituto Nacional da Propriedade Industrial (INPI), DIRPA / DQUIM II, \\ Phone: +(55) (21) 9300-0623, Praça Mauá 07, Centro, Rio de Janeiro - RJ, Brazil. \\ E-mail: sergiob@inpi.gov.br \\ ${ }^{3}$ Universidade Estadual de Campinas, UNICAMP, Faculdade de Engenharia Química (FEQ), PQGe \\ Phone: +(55) (19) 35213855, Av. Albert Einstein, 500, Cidade Universitária Zeferino Vaz, \\ CEP: 13083-970, Cx. P. 6066, Campinas - SP, Brazil. E-mail: clquintani@yahoo.com.br
}

(Received: December 12, 2005 ; Accepted: December 5, 2006)

\begin{abstract}
Cyclone models have been used without relevant modifications for more than a century. Most of the attention has been focused on finding new methods to improve performance parameters. Recently, some studies were conducted to improve equipment performance by evaluating geometric effects on projects. In this work, the effect of cyclone geometry was studied through the creation of a symmetrical inlet and a volute scroll outlet section in an experimental cyclone and comparison to an ordinary single tangential inlet. The study was performed for gas-solid flow, based on an experimental study available in the literature, where a conventional cyclone model was used. Numerical experiments were performed by using CFX 5.7.1. The axial and tangential velocity components were evaluated using RSM and LES turbulence models. Results showed that these new designs can improve the cyclone performance parameters significantly and very interesting details were found on cyclone fluid dynamics properties using RSM and LES.
\end{abstract}

Keywords: CFD; Cyclones; Performance; RSM; LES.

\section{INTRODUCTION}

Cyclones are widely used for removal dust of gaseous flows in industrial processes. Cyclone dust collectors have been used in many industrial facilities to collect solid particles from gas-solid flows and to reduce air pollution originating in chimney smoke from chemical plant drier equipment (Ogawa, 1997). Currently, with new engineering applications of cyclones as dryers, reactors and particularly in the removal of high-cost catalysts from gases in petroleum refineries, industries require a greater understanding of turbulent gas flows, which could lead to rigorous procedures capable of accurately predicting efficiency, velocity and pressure fields (Meier and Mori, 1999).

There are many types of cyclones for the purpose of solid particle separation. However, the following are the most typical: returned flow or reversed flow, axial flow and rotary flow with tangential injection of the second gas flow into the cyclone body. The standard kind of cyclone (composed of tangential inlet pipe to the main body for generating the rotational gas flow inside the equipment) has an exit

*To whom correspondence should be addressed 
pipe, cone and dust bunker. Ogawa and Hikichi (1981) proposed that the solid particles entering the cyclone immediately bifurcate into two layers of dust due to the eddy current based on the secondary flow on the upper cover surface in the coaxial space between cyclone body and exit pipe. One of them goes around the coaxial space on the upper cover surface and rotates around the exit pipe with the gas flow. The other rotates and descends along the surface of the cyclone body. Then, on the surface of the cone, the dust layer, which is pressed onto the cone surface by the centrifugal force, descends aided by gravitational force and descending airflow in the boundary layer. Lastly, these dust layers are deposited in the dust bunker (Zhou and Soo, 1990). However, some of the deposited dust rolls up from this dust layer by the secondary flow in the boundary and flows through the exit pipe. Centrifugal effects, which are responsible for collecting fine particles, depend directly on the tangential velocity of the solid particles. Therefore, the tangential velocity of the gas flow, which relates to the pressure drop, must be increased in order to increase cyclone efficiency. These processes are the mechanism of separation of solid particles in cyclones.

The historical transition of cyclones development can be found in Crawford (1976), Storch (1979) and Ogawa (1984), where many old and interesting types of cyclones are discussed. The most standard construction of the returned flow type is composed of a cylindrical body with a fixed diameter and a conical part. Physical models or families of cyclones are established when a set of dimensions is fixed in relation to the diameter. There are various cyclone models in the literature, but the most famous are the Stairmand (1951) and the Lapple (1951) ones. These cyclones were developed through experimental tests with the aim was performance optimize. However, according to Dirgo and Leith (1985), there is no theoretical base to assure that a specific model has all high performance characteristics. The advantage of using this cyclones model is that its performance properties are supported by many studies found in the literature.

Since its conception over a century ago, many researchers have contributed to the large volume of work on improving the efficiency of cyclones by introducing new design and operation variables (Jo et al., 2000). However, in most cases, the improvement in efficiency is marginal and in some cases it is associated with complex structure and additional operating costs (Gregg, 1995).

A good understanding of the fluid dynamics in a cyclone is required in order to make further design improvements. Analytical techniques do not permit variations in the geometry to be readily assessed.
Computational fluid dynamics (CFD) models provide an economical means of understanding the complex fluid dynamics and how it is influenced by changes in both design and operating conditions.

The first application of CFD techniques to cyclone simulation was presented by Boysan et al. (1982). After this pioneering work, several studies were done on turbulence modeling in order to improve through prediction of velocity and pressure fields to modify the turbulence models.

If the inlet duct is ignored, cyclone shape is almost ax-symmetric and a number of previous CFD models used this feature in order to simplify the model to a two-dimensional case (Duggins and Frith, 1987). While this greatly reduces computational time, a twodimensional model is limited, since the inlet duct location will break the flow pattern symmetry. Furthermore such simplifications can not be used to assess changes in the inlet design or offset vortex finders (Witt et al., 1999). The recent increase in computing power and grid generation capabilities have allowed the latest CFD models to include the full threedimensional shape and to be used for evaluating design modifications. The lack of high- quality measurements of the flow field in cyclones has limited the validation of past models (Witt et al., 1999).

In this work, some effects of an additional symmetrical inlet and a scroll outlet section are presented. The starting point was based on some works available in the literature (Patterson and Munz, 1989; Zhao et al., 2004 and Bernardo, 2005). Numerical simulations of gas-solid flow phase were carried out using CFX 5.7.1, a CFD code available on the market. For the turbulence model, the RSM and LES formulations were tested using a refined grid and data on fluid dynamics properties and performance parameters (collection efficiency and pressure drop) were obtained.

\section{MATHEMATICAL MODELING}

The conservation equations of the flow-involved phases can be written in a generalized form in this work. In a Eulerian-Eulerian model, the Reynolds averaged equations have been used, as follows:

$$
\begin{aligned}
& \frac{\partial \rho_{\alpha}}{\partial \mathrm{t}}+\nabla \cdot\left(\rho_{\alpha} \mathrm{u}_{\alpha}\right)=0 . \\
& \frac{\partial \rho_{\alpha} \mathrm{u}_{\alpha}}{\partial \mathrm{t}}+\nabla \cdot\left(\rho_{\alpha} \mathrm{u}_{\alpha} \mathrm{u}_{\alpha}\right)=-\nabla \mathrm{p}_{\alpha}+ \\
& +\nabla \cdot \mu_{\alpha} \nabla \mathrm{u}_{\alpha}-\nabla \cdot\left(\rho_{\alpha} \overline{\mathrm{u}_{\alpha}^{\prime} \mathrm{u}_{\alpha}^{\prime}}\right)
\end{aligned}
$$


where the subscript $\alpha$ represents the generic phase (solid or gas), $\rho$ is the density of generic phase $\alpha, t$ represents the time and $\mu$ is the viscosity. Finally, $u$ represents the velocity vector, defined by Reynolds averaged equation as (see Meier and Mori, 1999).

$\mathrm{u}=\overline{\mathrm{u}}+\mathrm{u}^{\prime}$

In equation (2) $\rho \overline{u^{\prime} u^{\prime}}$ is the Reynolds stress tensor.

These equations are applicable to incompressible and transient cyclone flow in 3D coordinate systems. The flow can be considered isothermal, thus the energy conservation equation can be neglected.

Numerical methods have been developed to solve the equations presented above, whose complexity is significantly increased due to the Reynolds stress terms on the right-hand side of Equation (2). For strongly swirling flows the standard k- $\varepsilon$ turbulence model is know to have limitations (Meier and Mori., 1999). In order to obtain values for the Reynolds stress terms, a turbulence model, known as the Reynolds stress model (RSM), was used here. To compare the results obtained with RSM, another turbulence model, known as the large eddy simulation (LES) model, was also used. These models will be described in the next section.

\section{Reynolds Stress Model}

This model is based on transport equations for all components of the Reynolds stress tensor and the respective dissipation rate. They are suitable for strongly anisotropic flows. This model does not use the eddy viscosity hypothesis. An equation for the transport of Reynolds stresses in the fluid is solved for the individual stress components.

The differential equations, given for each component of the Reynolds stresses, were developed and their solution provides each stress component, allowing anisotropy in the turbulent stress terms. More details on this development can be found in Meier and Mori (1999), Bernardo (2005), Bernardo et al. (2006) and ANSYS ${ }^{\circledR}$ CFX $^{\circledR}-5.7^{\mathrm{TM}}$ Users Guide.

$$
\begin{aligned}
& \frac{\partial \rho \overline{\mathrm{u}_{\mathrm{i}} \mathrm{u}_{\mathrm{j}}}}{\partial \mathrm{t}}+\frac{\partial}{\partial \mathrm{x}_{\mathrm{k}}}\left(\mathrm{U}_{\mathrm{k}} \rho \overline{\mathrm{u}_{\mathrm{i}} \mathrm{u}_{\mathrm{j}}}\right)=\mathrm{P}_{\mathrm{ij}}+\phi_{\mathrm{ij}}+ \\
& +\frac{\partial}{\partial \mathrm{x}_{\mathrm{k}}}\left[\left(\mu+\frac{2}{3} \mathrm{c}_{\mathrm{s}} \rho \frac{\mathrm{k}^{2}}{\varepsilon}\right) \frac{\partial \rho \overline{\mathrm{u}_{\mathrm{i}} \mathrm{u}_{\mathrm{j}}}}{\partial \mathrm{x}_{\mathrm{k}}}\right]-\frac{2}{3} \delta_{\mathrm{ij}} \varepsilon \rho
\end{aligned}
$$

Here, $\phi_{\mathrm{ij}}$ is the pressure-strain correlation, $\mathrm{k}$ is the turbulent kinetic energy, $\varepsilon$ is the dissipation rate of turbulent kinetic energy and $\mathrm{P}$, the exact production term. $\mathrm{P}$ and $\mathrm{k}$ are given by

$$
\mathrm{P}=-\rho\left(\overline{\mathrm{u} \cdot \mathrm{u}}(\nabla \mathrm{U})^{\mathrm{T}}+(\nabla \mathrm{U}) \overline{\mathrm{u} \cdot \mathrm{u}}\right)
$$

$\frac{\partial\left(\overline{\rho_{\mathrm{k}}} \mathrm{k}_{\mathrm{k}}\right)}{\partial \mathrm{t}}+\nabla \cdot\left(\overline{\rho_{\mathrm{k}}} \overline{v_{\mathrm{k}}} \mathrm{k}_{\mathrm{k}}\right)=$

$$
=\nabla \cdot\left(\frac{\mu_{\mathrm{k}}^{\mathrm{ef}}}{\sigma^{\mathrm{k}}} \nabla \mathrm{k}\right)+\left[\mathrm{G}_{\mathrm{k}}-\overline{\rho_{\mathrm{k}}} \varepsilon_{\mathrm{k}}\right]
$$

As the turbulence dissipation appears in the individual stress equations, an additional equation for $\varepsilon$ is still required:

$$
\begin{aligned}
& \frac{\partial \rho \varepsilon}{\partial \mathrm{t}}+\nabla \cdot(\rho \mathrm{U} \varepsilon)=\frac{\varepsilon}{\mathrm{k}}\left(\mathrm{c}_{\varepsilon 1} \mathrm{P}-\mathrm{c}_{\varepsilon 2} \rho \varepsilon\right)+ \\
& +\nabla \cdot\left[\frac{1}{\sigma_{\varepsilon \mathrm{RS}}}\left(\mu+\rho \mathrm{C}_{\mu \mathrm{RS}} \frac{\mathrm{k}^{2}}{\varepsilon}\right) \nabla \cdot \varepsilon\right]
\end{aligned}
$$

In these equations, the anisotropic diffusion coefficients of the original models are replaced by an isotropic formulation, which increases the robustness of RSM. The model constants were obtained from ANSYS $^{\circledR}$ CFX $^{\circledR}-5.7^{\mathrm{TM}}$ Users Guide and are presented:

$\mathrm{c}_{\mathrm{S}}=0.22 ; \quad \mathrm{c}_{\varepsilon 1}=1.45 ; \quad \mathrm{c}_{\varepsilon 2}=1.9 ; \quad \mathrm{C}_{\mu \mathrm{RS}}=0.1152$.

\section{Large Eddy Simulation}

Large eddy simulation (LES) starts from the same set of differential equations, but improves the movement equations by filtering and performing the decomposition of the variables on a large scale (resolved) and a small scale (unresolved). The LES model was intended primarily for research purposes and single-phase, single-component and non-reacting flow simulations (ANSYS ${ }^{\circledR}$ CFX $^{\circledR}-5.7^{\mathrm{TM}}$ Users Guide). LES is an approach which solves for the large-scale fluctuating flows and uses "subgrid" scale turbulence models for the small-scale motion. With these methods, time-dependent equations are solved for the turbulent motion with either no approximations and all large scales resolved; the equations are filtered in some way to remove very 
fine time and length scales $\left(\mathrm{ANSYS}^{\circledR} \mathrm{CFX}^{\circledR}-5.7^{\mathrm{TM}}\right.$ Users Guide).

Any flow variable $\mathrm{f}$ can be written as:

$\mathrm{f}=\overline{\mathrm{f}}+\mathrm{f}^{\prime}$

where $\mathrm{f}^{\prime}$ is the small scale part, and $\overline{\mathrm{f}}$, the large scale part, is defined through volume averaging as

$$
\bar{f}\left(x_{i}, t\right)=\int_{V o l} G\left(x_{i}-x_{i}{ }^{\prime}\right) f\left(x_{i}{ }^{\prime}, t\right) d x_{i}{ }^{\prime}
$$

where $G\left(x_{i}-x_{i}{ }^{\prime}\right)$ is the filter function (called the hat filter or Gaussian filter).

After volume averaging and neglecting density fluctuations, the filtered Navier-Stokes equation becomes

$$
\frac{\partial\left(\rho \overline{\mathrm{U}}_{\mathrm{i}}\right)}{\partial \mathrm{t}}+\frac{\partial\left(\rho \overline{\mathrm{u}_{\mathrm{i}} \mathrm{u}_{\mathrm{j}}}\right)}{\partial \mathrm{x}_{\mathrm{j}}}=-\frac{\partial \overline{\mathrm{p}}}{\partial \mathrm{x}_{\mathrm{i}}}+\mu \frac{\partial^{2} \overline{\mathrm{U}_{\mathrm{i}}}}{\partial \mathrm{x}_{\mathrm{j}} \partial \mathrm{x}_{\mathrm{j}}}
$$

As described above, turbulence models seek to solve a modified set of transport equations by introducing averaged and fluctuating components. For example, a velocity $U$ may be divided into an average component $\bar{U}$ and a time varying component, u', so

$\mathrm{U}=\overline{\mathrm{U}}+\mathrm{u}^{\prime}$

The non linear transport term in the filtered equation can be developed as

$$
\begin{aligned}
& \overline{u_{i} u_{j}}=\overline{\left(\overline{U_{i}}+u_{i}{ }^{\prime}\right)\left(\overline{U_{j}}+u_{j}{ }^{\prime}\right)}=
\end{aligned}
$$

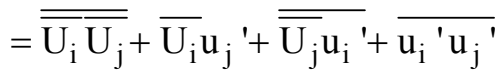
(1)
(2)
(3)

In time averaging the terms (2) and (3) vanish, but when using volume averaging this is no longer true. Introducing the subgrid scale (SGS) stresses, $\tau_{\mathrm{ij}}$, as

$$
\tau_{\mathrm{ij}}=\overline{\mathrm{u}_{\mathrm{i}} \mathrm{u}_{\mathrm{j}}}-\overline{\mathrm{U}_{\mathrm{i}}} \overline{\mathrm{U}_{\mathrm{j}}}
$$

we can rewrite the filtered Navier Stokes equations as

$$
\frac{\partial\left(\rho \overline{\mathrm{U}_{\mathrm{i}}}\right)}{\partial \mathrm{t}}+\frac{\partial\left(\rho \tau_{\mathrm{ij}}+\rho \overline{\mathrm{U}_{\mathrm{i}} \overline{\mathrm{U}_{j}}}\right)}{\partial \mathrm{x}_{\mathrm{j}}}=-\frac{\partial \overline{\mathrm{p}}}{\partial \mathrm{x}_{\mathrm{i}}}+\mu \frac{\partial^{2} \overline{\mathrm{U}_{\mathrm{i}}}}{\partial \mathrm{x}_{\mathrm{j}} \partial \mathrm{x}_{\mathrm{j}}}
$$

$$
\frac{\partial\left(\rho \overline{\mathrm{U}_{\mathrm{i}}}\right)}{\partial \mathrm{t}}+\frac{\partial\left(\rho \overline{\mathrm{U}_{\mathrm{i}} \mathrm{U}_{\mathrm{j}}}\right)}{\partial \mathrm{x}_{\mathrm{j}}}=-\frac{\partial \overline{\mathrm{p}}}{\partial \mathrm{x}_{\mathrm{i}}}+\mu \frac{\partial^{2} \overline{\mathrm{U}_{\mathrm{i}}}}{\partial \mathrm{x}_{\mathrm{j}} \partial \mathrm{x}_{\mathrm{j}}}-\frac{\partial\left(\rho \tau_{\mathrm{ij}}\right)}{\partial \mathrm{x}_{\mathrm{j}}}
$$

with

$$
\begin{aligned}
& \tau_{\mathrm{ij}}=\overline{\mathrm{u}_{\mathrm{i}} \mathrm{u}_{\mathrm{j}}}-\overline{\mathrm{U}_{\mathrm{i}}} \overline{\mathrm{U}_{\mathrm{j}}} \\
& =\overline{\overline{\mathrm{U}_{\mathrm{i}} \bar{U}_{\mathrm{j}}}}+\overline{\overline{\mathrm{U}_{\mathrm{i}} \mathrm{u}_{\mathrm{j}}{ }^{\prime}}}+\overline{\overline{\mathrm{U}_{\mathrm{j}} \mathrm{u}_{\mathrm{i}}{ }^{\prime}}}+\overline{\overline{\mathrm{u}_{\mathrm{i}}{ }^{\prime} \mathrm{u}_{\mathrm{j}}{ }^{\prime}}}-\overline{\mathrm{U}_{\mathrm{i}}} \overline{\mathrm{U}_{\mathrm{j}}} \\
& =\mathrm{L}_{\mathrm{ij}}+\mathrm{C}_{\mathrm{ij}}+\mathrm{R}_{\mathrm{ij}} \\
& \mathrm{L}_{\mathrm{ij}}=\overline{\overline{\mathrm{U}_{\mathrm{i}} \overline{\mathrm{U}_{\mathrm{j}}}}}-\overline{\mathrm{U}_{\mathrm{i}}} \overline{\mathrm{U}}=\text { Leonard Stresses } \\
& \mathrm{C}_{\mathrm{ij}}=\overline{\overline{\mathrm{U}_{\mathrm{i}}} \mathrm{u}_{\mathrm{j}}{ }^{\prime}}+\overline{\overline{\mathrm{U}_{\mathrm{j}}} \mathrm{u}_{\mathrm{i}}{ }^{\prime}}=\text { Cross Terms } \\
& R_{i j}=\overline{u_{i}{ }^{\prime} u_{j}{ }^{\prime}}=S G S \text { Re ynolds Stresses }
\end{aligned}
$$

The LES approaches require fine grids and small time steps, particularly for wall-bounded flows. However, they can give details on the structure of turbulent flows, such as pressure fluctuations, which can not be obtained from RANS formulation.

\section{a) Smagorinsky Model}

The Smagorinsky model can be thought of as combining the Reynolds averaging assumptions given by $\mathrm{L}_{\mathrm{ij}}+\mathrm{C}_{\mathrm{ij}}=0$ with a mixing length-based eddy viscosity model for the Reynolds SGS tensor. It is thereby assumed that the SGS stresses are proportional to the modulus of the strain rate tensor, $\overline{\mathrm{S}}_{\mathrm{ij}}$, of the filtered large-scale flow:

$\tau_{\mathrm{ij}}=-\frac{1}{3} \tau_{\mathrm{kk}}=-2 \cdot \mathrm{v}_{\mathrm{SGS}} \cdot \overline{\mathrm{S}}_{\mathrm{ij}}=\mathrm{v}_{\mathrm{SGS}} \cdot\left(\frac{\partial \overline{\mathrm{U}_{\mathrm{i}}}}{\partial \mathrm{x}_{\mathrm{j}}}+\frac{\partial \overline{\mathrm{U}_{\mathrm{j}}}}{\partial \mathrm{x}_{\mathrm{i}}}\right)$

To close the equation, we need a model for the SGS viscosity $\boldsymbol{v}_{S G S}$. Based on dimensional analysis the SGS viscosity can be expressed as

$\mathrm{v}_{\mathrm{SGS}} \propto 1 \mathrm{q}_{\mathrm{SGS}}$

where 1 is the length scale of the unresolved motion (usually the grid size $\mathrm{D}=(\mathrm{Vol})^{1 / 3}$ ) and $\mathrm{q}_{\mathrm{SGS}}$ is the velocity of the unresolved motion.

In the Smagorinsky model, based on an analogy to the Prandtl mixing length model, the velocity scale is related to the gradients of the filtered velocity: 
$\mathrm{q}_{\mathrm{SGS}}=\Delta|\overline{\mathrm{S}}|$

where

$$
|\overline{\mathrm{S}}|=\left(2 \overline{\mathrm{S}}_{\mathrm{ij}} \overline{\mathrm{S}}_{\mathrm{ij}}\right)^{1 / 2}
$$

This yields the Smagorinsky model for the SGS viscosity:

$$
\mathrm{v}_{\mathrm{SGS}}=\left(\mathrm{C}_{\mathrm{S}} \Delta\right)^{2}|\overline{\mathrm{S}}|
$$

where $C_{S}$ is the Smagorinsky constant. The value of the Smagorinsky constant for isotropic turbulence with inertial range spectrum is

$$
\mathrm{E}(\mathrm{k})=\mathrm{C}_{\mathrm{k}} \varepsilon^{2 / 3} \mathrm{k}^{-5 / 3}
$$

with

$$
\mathrm{C}_{\mathrm{S}}=\frac{1}{\pi}\left(\frac{2}{3 \mathrm{C}_{\mathrm{k}}}\right)^{3 / 4}=0.18
$$

For practical calculations the value of $C_{S}$ is changed depending on the type of flow and mesh resolution. Its value is found to vary between a value of 0.065 (channel flows) and 0.25 . Often a value of 0.1 is used. The equations 8-22 cited here are referenced in ANSYS ${ }^{\circledR} \mathrm{CFX}^{\circledR}-5.7^{\mathrm{TM}}$ Users Guide.

\section{NUMERICAL METHODS}

The equations presented in part 2 were solved numerically using the commercial CFD code CFX, in which the control volume method is used to discretize the transport equations. The pressure-velocity coupling algorithm SIMPLEC (SIMPLE Consistent) and the higher upwind interpolation scheme were used in all numerical experiments. More details on these schemes can be found in Patankar (1980).

Time steps of 0.001 seconds and a total simulation time of 12 seconds were used. A transient run was performed, using the steady-state results for initial conditions, with four iterations for each time step. Numerical experiments were carried out with an accuracy of $10^{-5}$ for the Euclidean norm of the mass source in the pressure-velocity coupling. A tight convergence criterion could be achieved using these conditions.

\section{Computational Grid and Boundary Conditions}

Table 1 shows the geometric properties of the cyclone used by Patterson and Munz (1989). It was the starting point for this study. Figure 1 shows the cyclone described in Table 1.

Table 1: Cyclone geometric configuration.

\begin{tabular}{|l|c|}
\hline Geometric Data & Dimension (m) \\
\hline Cyclone diameter & 0.102 \\
Diameter of the top exit pipe ("overflow") & 0.0508 \\
Diameter of the bottom exit pipe ("underflow") & 0.0254 \\
Height of the cylindrical region & 0.1522 \\
Height of the inlet rectangular section & 0.0508 \\
Height of the top exit pipe ("overflow") & 0.108 \\
Height of the conical region & 0.203 \\
\hline
\end{tabular}

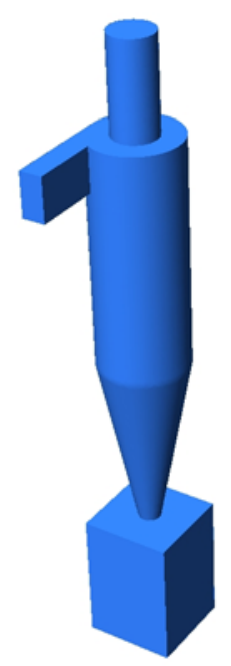

Figure 1: Basic cyclone proposed by Patterson and Munz (1989). 
Starting from the geometry proposed by Patterson and Munz (1989), some modifications of this geometry that were proposed in the literature (Zhao et al., 2004) were added. The first was the creation of a symmetrical tangential inlet by splitting the inlet into two opposite ones, and the second was the substitution of inlet and outlet ducts by volute ones. All other cyclone parameters were maintained unchanged. The study was carried out using
Patterson and Munz (1989) as reference to validate the model proposed in this work.

Figures 2 and 3 show these cases. The case proposed in Figure 2 was based on Zhao et al. (2004), and that proposed in Figure 3 represents a scale-down of an industrial application. For all cases presented in Figures 1, 2 and 3, grids with tetrahedral elements were built using Ansys ICEM CFD 5.0. Table 2 shows the characteristics of the grids.

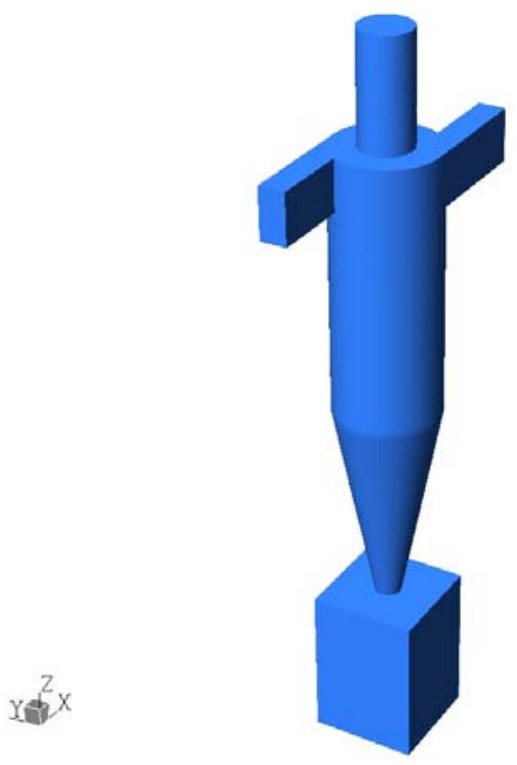

Figure 2: Symmetrical inlet section as proposed by Zhao et al. (2004) and adapted here to the cyclone of Patterson and Munz (1989).

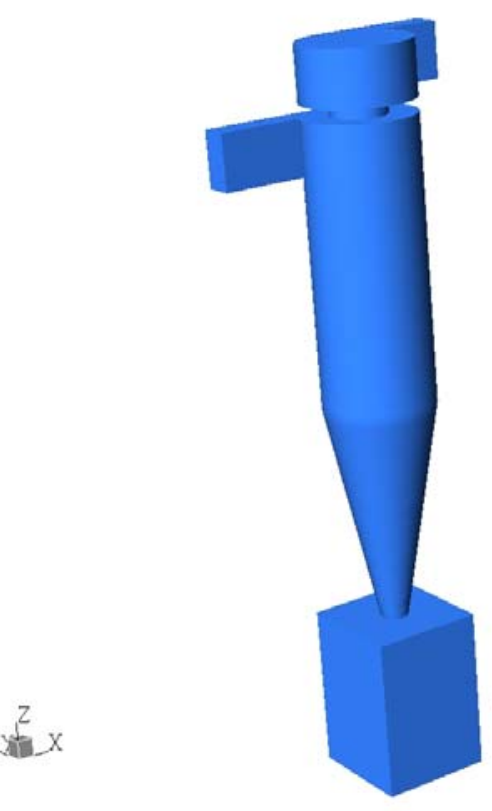

Figure 3: Outlet section proposed here with the Patterson and Munz (1989) cyclone dimensions. 
Table 2: Grid characteristics.

\begin{tabular}{|l|c|}
\hline \multicolumn{1}{|c|}{ Case Proposed } & Number of Elements on the Grid \\
\hline Case 1: normal cyclone as proposed by Patterson and Munz (1989) & $2,484,087$ \\
Case 2: additional symmetrical inlet section as proposed by Zhao et al. (2004) & $2,639,830$ \\
Case 3: volute inlet and outlet section & $2,735,208$ \\
\hline
\end{tabular}

The effect of grid refinement had previously been evaluated in the simulation process.

Because the LES formulation was applied, the grids presented in Table 2 are very refined, compared to other former simulations. Martignoni et al. (2005) used the same cases as those presented in Table 2, but the grids were not so refined (they had around 30\% cells compared to the present one). It was found that the LES formulation requires very refined grids to obtain the best results for this type of study.

As boundary conditions, data used by Patterson and Munz (1989) and applied in the cases studied in this work are shown in Table 3.

Furthermore, the numerical computation ignored particle size distribution and used an average particle size of $10 \mu \mathrm{m}$, obtained from a grade efficiency curve provided by Patterson and Munz (1989). The solid phase was considered an inviscid fluid with an inlet volume fraction of $6.13 \cdot 10^{-5}$.

For case 2 (symmetrical inlet) the total flux was divided by 2 . Then, initial velocity in this case was $7.6 \mathrm{~m} / \mathrm{s}$ at both inlets. The boundary conditions for inflow velocities and volume fraction at the cyclone inlet were assumed to be uniform. The boundary conditions for the solid phase were similar to those for the gas phase, except for the axial velocity at the wall, where the free slip condition was used. At the walls "no slip" condition was used for the gas phase and "free slip" for the solid phase. The outlet boundary condition was set at atmospheric pressure

Table 3: Boundary conditions.

\begin{tabular}{|c|l|c|}
\hline \multicolumn{2}{|c|}{ Properties } & Patterson and Munz (1989) \\
\hline & Material & silica \\
& Solid velocity & $15.2 \mathrm{~m} / \mathrm{s}$ \\
& Solid mass concentration & $40 \mathrm{~g} / \mathrm{m}^{3}$ \\
& Medium diameter & $10 \mu \mathrm{m}$ \\
& Density & $2600 \mathrm{~kg} / \mathrm{m}^{3}$ \\
& Viscosity & $10.8 .10^{-9} \mathrm{~kg} / \mathrm{m} \mathrm{s}^{3}$ \\
& Solid flow & $3.18 .10^{-6} \mathrm{~m}^{3} / \mathrm{h}$ \\
& Volume fraction & $6.13 .10^{-5}$ \\
\hline \multirow{3}{*}{ Gas Phase } & Material & air \\
& Gas velocity & $15.2 \mathrm{~m} / \mathrm{s}$ \\
& Density & $1.142 \mathrm{~kg} / \mathrm{m}^{3}$ \\
& Gas flow & $1.96 .10^{-2} \mathrm{~m}^{3} / \mathrm{s}$ \\
\hline
\end{tabular}

\section{RESULTS AND DISCUSSION}

\section{Turbulence Model Validation for 3-D Flows}

Turbulence models applied in the present work were validated by Bernardo et al. (2005) Bernardo (2005) and Bernardo et al. (2006). In these studies, the authors used previous numerical simulation involving the RSM and LES formulation in the cyclone proposed by Patterson and Munz (1989). Additional details can be seen in the literature cited.

\section{Convergence and Stability for Solution}

Simulation tests were carried out for a transient state. The Eulerian-Eulerian formulation was used for both continuous and dispersed phase flow to perform the numerical simulations. To study the 
phase dispersed particle trajectory, the Lagrangian approach was used. In order to guarantee the convergence and stability of the simulation, we verified the relation between pressure drop and overall collection efficiency with real simulated time. This test provided a way of tracking the progress of real time during the simulation. Figure 4 shows how performance parameters behave with time, for the initial $5 \mathrm{~s}$ of real simulated time. We can see in Figure 4 that when the real time is $1.3 \mathrm{~s}$, performance parameters reach a specified value and do not change with time. This means that the numerical solution was stabilized and convergence was reached. Figure 4 refers to case 2 (symmetrical inlet section), but it was also observed for the others three cases described in the Table 2, when both the RSM and the LES turbulence models were applied.

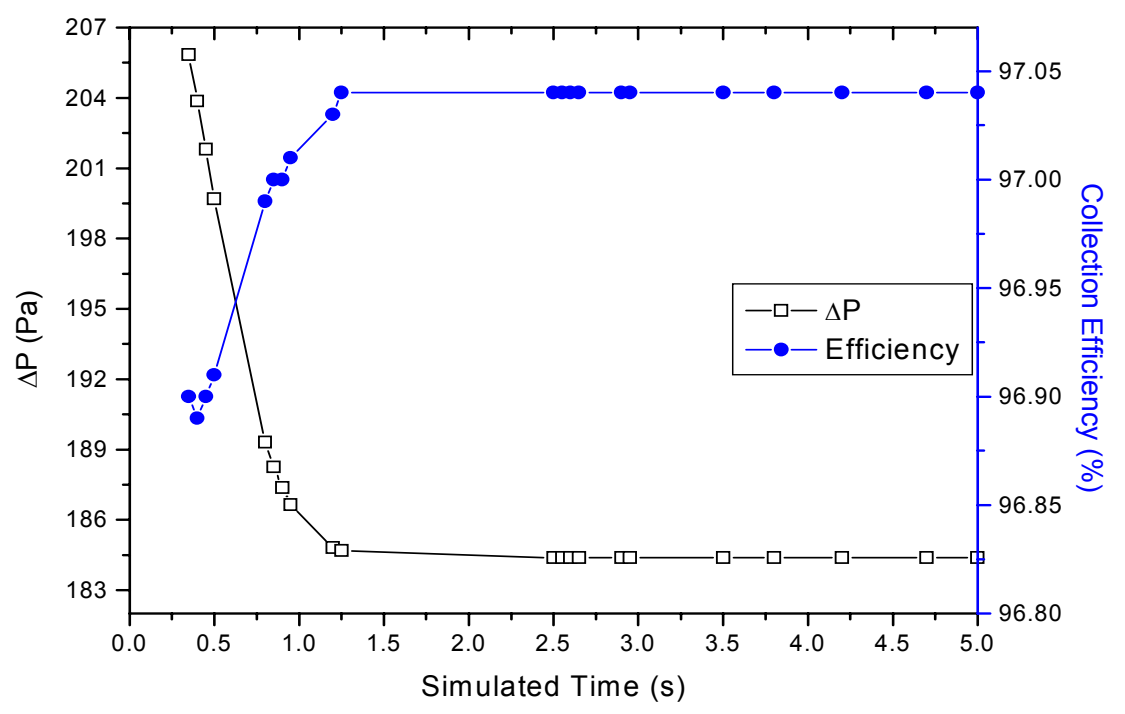

Figure 4: Performance parameters profile. Case 2: cyclone with symmetrical inlet section using the LES model.

\section{Qualitative Results: Fluid Dynamics Profiles}

In this section, the numerical results for the gassolid flow in the three types of cyclones are presented. The initial total velocity for both gas and solid phases was $15.2 \mathrm{~m} / \mathrm{s}$. Figure 5 shows the maps of tangential velocity for case 1 . In this figure, we can see that the LES turbulence model was able to show the profile for gas flow inside the cyclone. It doesn't appear to be continuous, but is winding with discontinued layers, while the RSM formulation did not show this important characteristic. Bernardo et al. (2005) observed this LES capability when working with inclined inlet section in the cyclone proposed by Patterson and Munz (1989).

For case 2 (symmetrical inlet) and case 3 (double volute cyclone) it was observed that the LES formulation did not have the same characteristics for the tangential velocity profile for gas phase in gas-solid flow as those in case 1 . The geometric characteristics proposed for cases 2 and 3 could be responsible for the effect. In comparison with the cyclone geometry presented in case 1 (see Figures 1 and 5), cases 2 and 3 modified respectively the inlet and the outlet track for gas flow inside the same cyclone. And in this case, there were no differences between the maps of tangential velocity for the RSM and LES formulations. In all numerical simulations, tests were carried out using very refined grids for both the LES and the RSM turbulence models. Thus, the absence of fluctuations observed for cases 2 and 3 confirms a relation between geometric characteristics and gas flow profile patterns. Figure 6 shows maps of tangential velocity for all three cases analyzed, using the LES turbulence model. In this figure, we can see exactly the influence of cyclone geometry on tangential velocity profiles. 


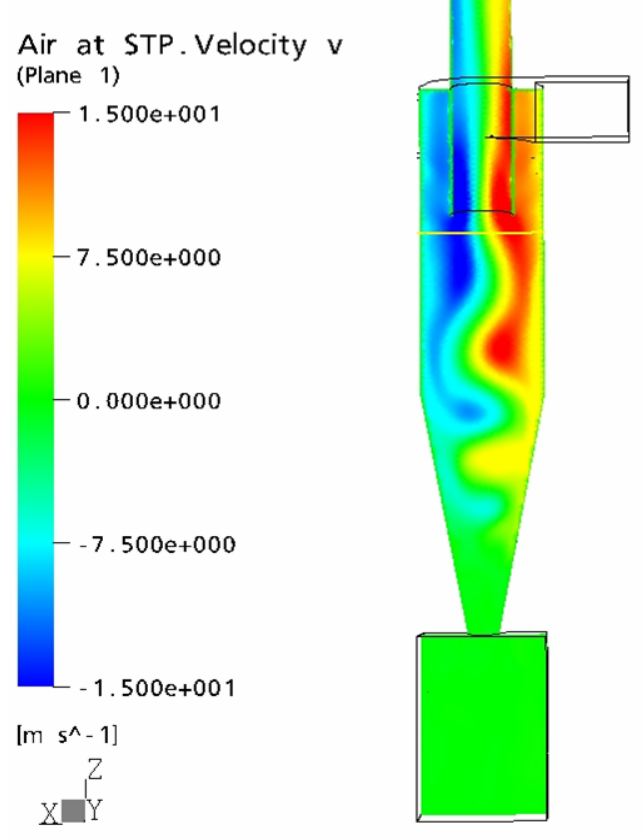

LES

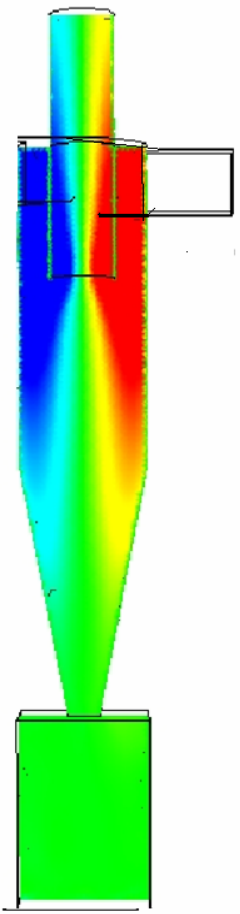

RSM

Figure 5: Maps of tangential velocity for case 1: conventional cyclone. Comparison between LES and RSM profiles.

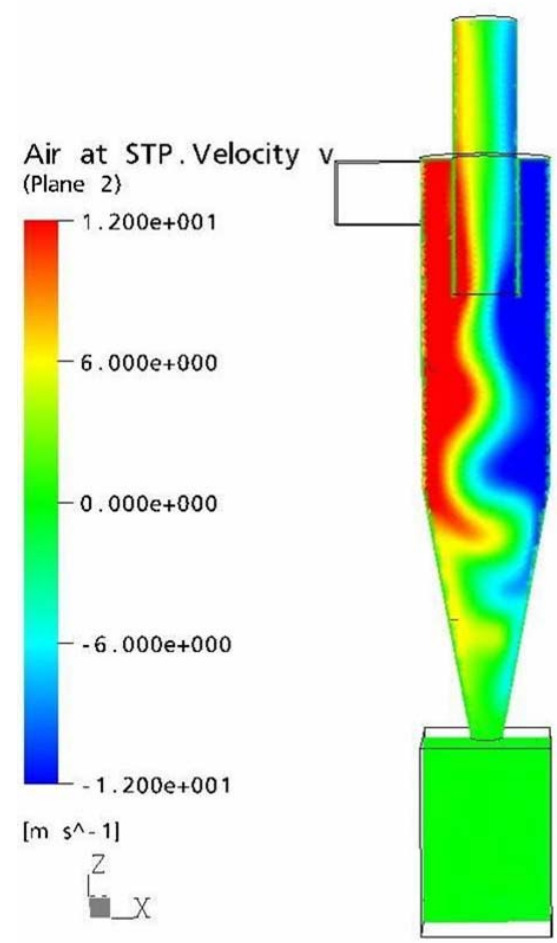

(A)

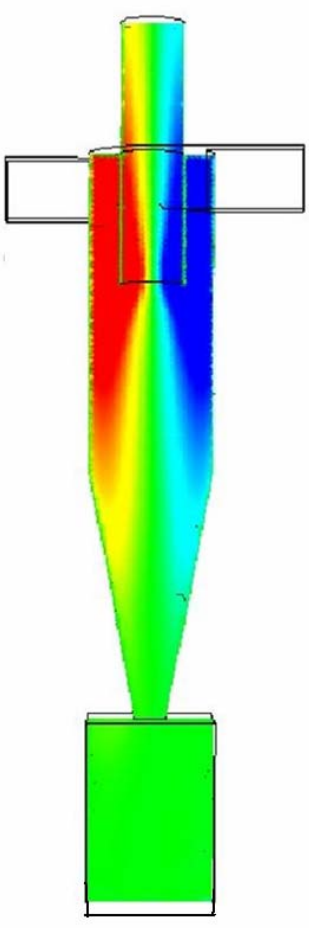

(B)

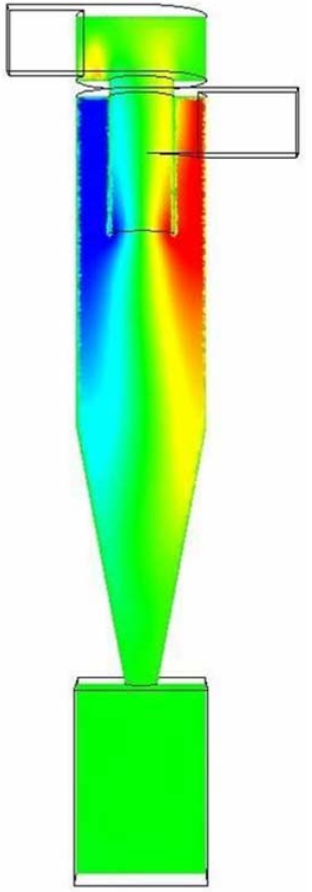

(C)

Figure 6: Maps of tangential velocity for all geometric cases using the LES formulation: (A) conventional cyclone; (B) symmetrical inlet; (C) scroll inlet and outlet section. 
Regarding the tangential velocity profile, there is no data available in Patterson and Munz (1989) for case 1 (conventional cyclone). We extract points for tangential velocity considering another study (Patterson and Munz, 1996), where the same conventional cyclone was used under the same operational conditions. In this work the authors used the axial position of $12 \mathrm{~cm}$ below the cylindrical cyclone body top. Figure 7 shows the numerical solutions obtained using the LES turbulence model for distributions of tangential velocity.

There is no experimental data available for comparison between numerical and experimental results. All results shown in Figure 7 are from numerical tests.

Figure 7 shows that results obtained on the capability of the turbulence model to represent the radial distributions of tangential velocities throughout the cyclone, where a good representation of the swirling flow with the tangential velocity peak like a Rankine curve, typical of flows in this kind of apparatus. The geometric modifications caused lower values of tangential velocity for gas phase in gas-solid flow, mainly for the symmetrical inlet option. When Figures 6 and 7 are analyzed together, we can conclude that the two proposed geometric modifications of the conventional cyclone used by Patterson and Munz (1989) were able to modify fluid dynamics patterns for gas flow inside this equipment. This will be reflected by the performance parameters. Figure 8 shows maps of pressure for numerical solutions in the three cyclones.

In Figure 8 we can observe that the total pressure drop decreases from the conventional cyclone to both new geometric design cyclones. Specially, the type with the symmetrical inlet has the lowest pressure drop of the proposed models. These facts are in agreement with the tendency of the tangential velocity profiles presented in Figure 7. The reduction in pressure drop obtained when modifications of conventional cyclone geometry are applied is a very important point to consider for improving the performance parameter of cyclones. Quantitative results for total pressure drop will be presented in the next section.

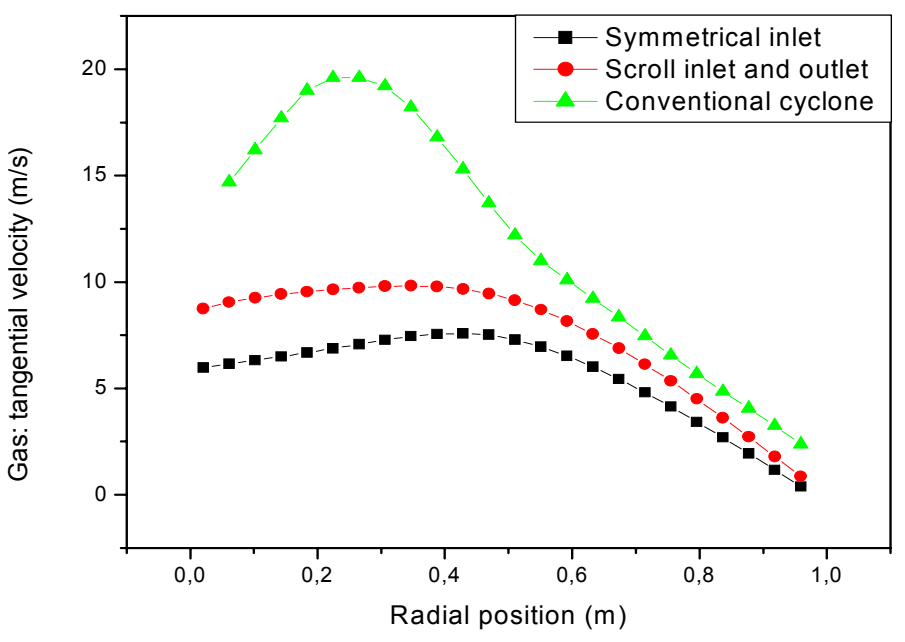

Figure 7: Tangential velocity for all geometric cases using the LES formulation.

\section{Quantitative Results: Cyclone Performance Parameters}

In Table 4 the performance parameters obtained for numerical simulations of all geometric types of cyclones studied in this work are presented. The overall collection efficiency of these cyclones was calculated based on work proposed in the literature. More details about this equation can be found in Bernardo (2005).

The solid phase was characterized by an average diameter with an inviscid behaviour. This average diameter was obtained from a grade efficiency curve by Patterson and Munz (1989). In order to predict the overall collection efficiency of the solid phase, it was assumed that all solid particles had the same diameter and that there was no interaction between the particles.

Experimental data presented in Table 4 were obtained from Patterson and Munz (1989) for the conventional cyclone. The numerical results for this case, represented by the conventional cyclone line in Table 4, showed good agreement with the experimental data. 

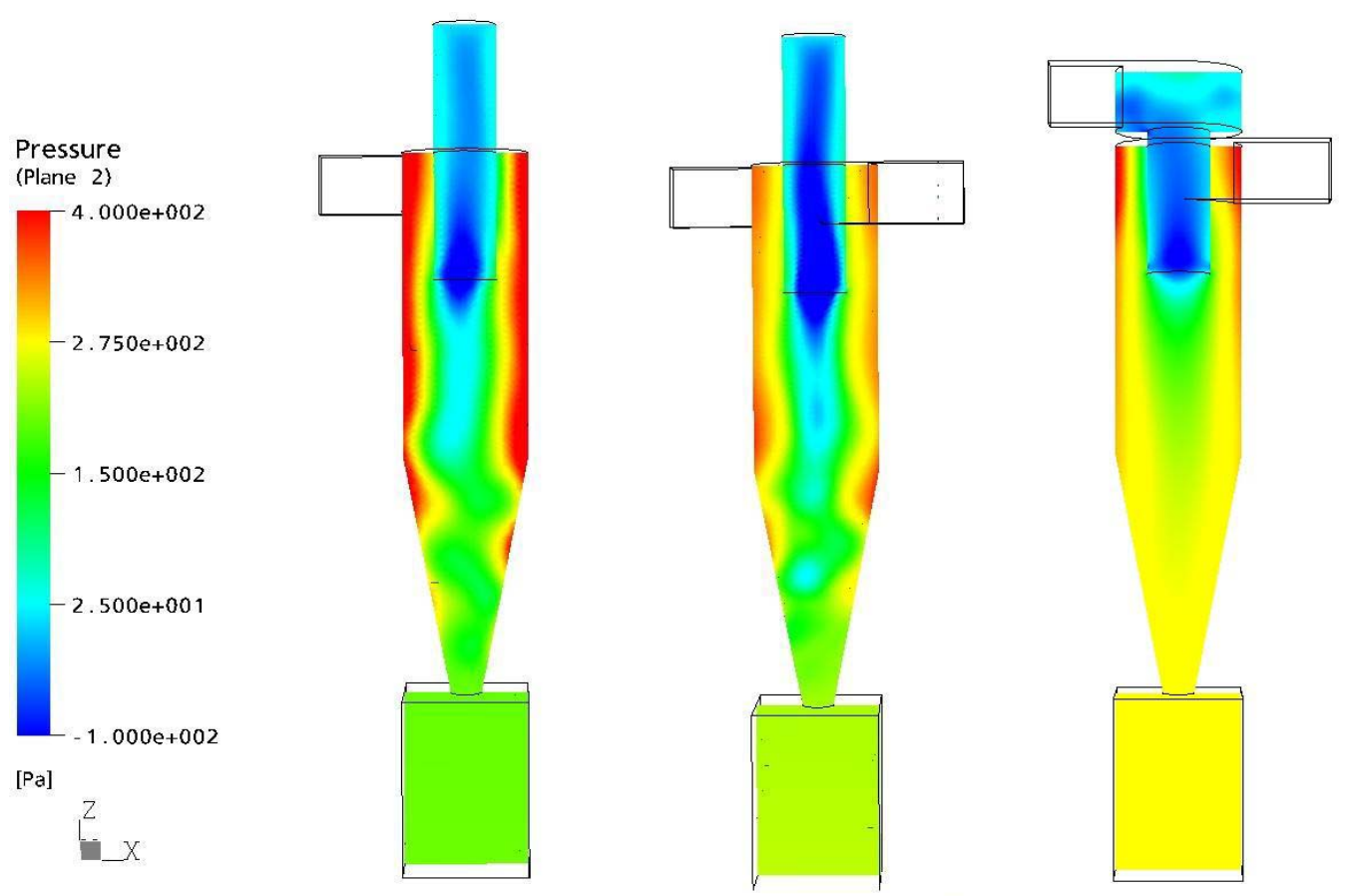

Figure 8: Maps of pressure for the numerical solutions: (a) conventional cyclone;

(b) symmetrical inlet; (c) scroll inlet and outlet.

Table 4: Performance parameters of the cyclone designs proposed.

\begin{tabular}{|l|c|c|c|c|}
\hline \multirow{2}{*}{} & \multicolumn{2}{|c|}{$\begin{array}{c}\text { Total Pressure Drop } \\
\text { (Pa) }\end{array}$} & \multicolumn{2}{c|}{$\begin{array}{c}\text { Overall Collection Efficiency } \\
\text { (\%) }\end{array}$} \\
\cline { 2 - 5 } & RSM & LES & RSM & LES \\
\hline Conventional Cyclone & 440 & 490 & 90.96 & 91.18 \\
Symmetrical Inlet & 182 & 184 & 97.04 & 97.03 \\
Volute Inlet and Outlet & 431 & 432 & 97.37 & 96.55 \\
\hline
\end{tabular}

The proposed modifications of the geometry of the conventional cyclone increased the overall cyclone collection efficiency. There are no significant differences between results for both the RSM and the LES turbulence models and the quantitative data. Bernardo et al. (2005) had observed this fact and concluded that the LES formulation is very useful to detect microscopic turbulent structures, while RSM does not detect them. Results in this work confirmed that the LES formulation contributes on qualitative data for fluid dynamics profiles on flow inside cyclones. However, the LES formulation required very refined grids. Therefore, computing costs to carry out the simulations were higher.

From these results we can see that the overall cyclone performance parameters studied here (pressure drop and collection efficiency) are influenced by cyclone geometric parameters. These parameters are significantly improved and offer an alternative in the study of cyclone design.

\section{CONCLUSIONS}

A new inlet and outlet design applied to conventional cyclones, including a double inlet section and a scroll inlet and outlet section, was presented and analyzed in this work, using very refined grids and the RSM and LES formulations as turbulence modeling.

Turbulence characteristics in the gas flow profiles were observed for the LES formulation, but not for the RSM formulation. In the study of new designs, 
these effects, indicating a relation between inlet or outlet cyclone geometry and gas flow profiles inside the cyclones, need to be considered.

Very good performance parameter results were obtained. It was verified that the overall cyclone collection efficiency increased and the pressure drop decreased for both formulations, but the design with two symmetrical inlets showed a large reduction in pressure drop than the other model.

All results indicate that these ideas can provide an alternative method for studying fluid dynamics inside cyclones and improve performance parameters. The next step in this work is to apply the proposed design procedure to different types of cyclones, specially industrial ones.

\section{REFERENCES}

Bernardo, S., Mori, M., Peres A.P. and Dionísio, R.P., (2006). "3-D Computational Fluid Dynamics of Gas and Gas-Particle Flows in a Cyclone with Different Inlet Section Angles". Powder Technology, vol. 162, Issue 3, pp. 190-200.

Bernardo, S., Peres, A.P. and Mori, M. (2005). Computational Study of Cyclone Flow Fluid Dynamics using a Different Inlet Section Angle. Thermal Engineering (RETERM), vol. 4, issue 1, p. 18 .

Bernardo, S. (2005). Estudo dos Escoamentos Gasoso e Gás-Sólido em Ciclones pela Aplicação de Técnicas de Fluidodinâmica Computacional. Ph.D Thesis, UNICAMP, Campinas-SP, Brazil, 273 p.

Boysan, F., Ayers, W.H. and Swithenbank, J.A. (1982). Fundamental Mathematical Modeling Approach to Cyclone Design. Inst. of Chemical Engineers, vol. 60, p. 222.

Crawford, M. (1976). Air Pollution Control Theory, McGraw-Hill.

Dirgo, J. and Leith, D. (1985). Performance of Theoretically Optimized Cyclones. Filtration and Separation, March/April, p. 119.

Duggins, R.K. and Frith, P.C.W. (1987). Turbulence Anisotropy in Cyclones. Filtration and Separation, Nov-Dez, pp .394.

Gregg, W.W. (1995). High Efficiency Cyclones for Powder Processing Applications, Adv. Filtration and Separation Technology, vol. 9, p. 240.

Jo, Y., Tien, C. and Ray, M.B. (2000). Development of a Post Cyclone to Improve the Efficiency of Reverse Flow Cyclones, Powder Technology, n.113, p. 97.
Lapple, C.E. (1951). Process use many collector types. Chemical Engineering, May, p. 144.

Martignoni, W.P., Bernardo, S. and Quintani, C.L. (2005). Evaluation of Geometric Modifications at an Experimental Cyclone using Computational Fluid Dynamics (CFD). Proceedings on $2^{\text {nd }} C F D$ Oil, Rio de Janeiro, RJ.

Meier, H.F. and Mori, M. (1999). Anisotropic Behavior of the Reynolds Stress in Gas and GasSolid Flows in Cyclones. Powder Technology, vol. 101, p. 108.

Ogawa, A. and Hikichi, T. (1981). Theory of CutSize of a Rotary Flow Dust Collector, Bulletin JSME, vol. 24, n. 188, p. 340.

Ogawa, A. (1984). Estimation of the Collection Efficiencies of the Three Types of the Cyclones Dust Collectors from the Standpoint of the Flow Patterns in the Cylindrical Cyclone Dust Collectors. Bulletin of JSME, vol. 27, n. 223, p. 64.

Ogawa, A. (1997). Mechanical Separation Process and Flow Patterns of Cyclone Dust Collectors. Ind. Applied Mech. Ver., vol. 50, n. 3, p. 97.

Patankar, S.V. (1980). Numerical Heat Transfer and Fluid Flow, Hemisphere Pub. Co., New York.

Patterson, P.A. and Munz, R.J. (1989). Cyclone Collection Efficiencies at Very High Temperatures. The Canadian Journal of Chemical Engineering, vol. 67, April, p. 321.

Patterson, P.A. and Munz, R.J. (1996). Gas and Particle Flow Patterns at Room and Elevated Temperatures. The Canadian Journal of Chemical Engineering, vol.74, April, p. 213.

Stairmand, C.J. (1951).The Design and Performance of Cyclone Separators. Trans. Inst. Chem. Eng., vol. 29 , p. 356.

Storch, O. (1979). Industrial Separators for Gas Cleaning, Elsevier .

Witt, P.J., Mittoni, L.J., Wu, J. and Shepherd, I.C. (1999). Validation of a CFD Model for Predicting Gas Flow in a Cyclone. Proceedings of CHEMECA99, Australia.

Zhao, B., Shen, H. and Kang, Y. (2004). Development of a Symmetrical Spiral Inlet to Improve Cyclone Separator Performance. Powder Technology, vol. 145, issue 1, pp. 47-50.

Zhou, L.X. and Soo, S.L. (1990). Theory Gas-Solid Flow and Collection of Solids in a Cyclone Separator. Powder Technology, vol. 63, p. 45.

\section{CONSULTING}

ANSYS $^{\circledR}$ CFX $^{\circledR}-5.7^{\mathrm{TM}}$ Users Guide. 